\title{
STUDIES ON THE NUTRITIONAL REQUIREMENTS OF BACTERIA VII. PYRIDINE-3-SULFONIC ACID AS A GROWTH FACTOR
}

\author{
DEN'ichi MIZUNO AND TOMIE NOJIMA \\ The National Institute of Health, \\ The Institute for Infectious Diseases, \\ Tokyo, Japan,
}

(Received June 2, 1952)

It has been well known that pyridine-3-sulfonic acid (PSA) is a growth inhibiting factor of some species of bacteria, reacting as an antagonist against niacin or its homologue.(13,24) On the other hand, interesting informations have recently been accumulated indicating that the same substance can work as a growth promoting factor when given in addition to niacin or at sufficiently low concentration. Namely, McIlwain (1940) (13) observed the growth stimulating effects of the combination of PSA and niacin on Staphylococcus and Proteus. Lwoff and Querido (1939) (7) reported that PSA, when added to culture medium for Proteus at the concentration of $10^{-5} \mathrm{M}$, could substitute niacin, although the data hereby obtained could not provide unequivocal evidence for its capability of being growth factor. ${ }^{(5)}$

Studies have been made in our laboratory to clarify whether and how PSA can exert growth stimulating effects on Staphylococcus. The present paper will discuss the results obtained therefrom. Our first experiments revealed that PSA can substitute niacinamide when used at the concentration of $10^{-4} \mathrm{M}$. It appears unlikely, however, that PSA can be converted to niacin, exchanging its sulfonyl with carboxyl radical, during the period of bacterial growth. Therefore, it was presumed that this phenomenon may be due to the change caused by PSA to the balance between the velocity of synthesis and degradation of niacin.

At the same time, in view of the fact that niacin homologues are the precursors for DPN, actually acting form as growth factor, it was also considered probable that the activities of DPN destructive enzymes, DPNnucleosidase ${ }^{(9,16)}$ and DPN-pyrophosphatase ${ }^{(6,21)}$, may be inhibited by the presence of PSA. The experimental results gave us suggestions verifying these presumptions. 
<smiles>O=C(O)c1cccnc1</smiles>

Nicotinic acid<smiles>NC(=O)c1cccnc1</smiles>

Nicotin amide<smiles>O=S(=O)(O)c1ccncc1</smiles>

Pyridine-3-sulfonic acid<smiles>NS(=O)(=O)c1cccnc1</smiles>

Pyridine-3-sulfona mide

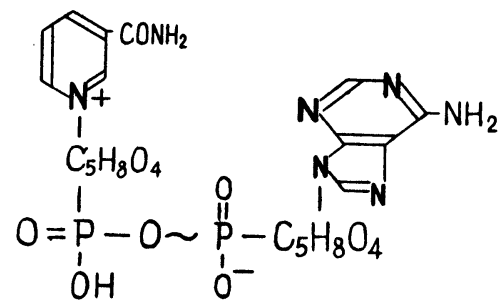<smiles>Cc1cc2c(cc1N)Nc1cc(N(C)C)ccc1N2</smiles>

Neutral red

DPN

\section{EXPERIMENTAL}

Strains: Staphylococcus aureus Terashima, Shigella dysenteriae I (Ewing I)

\section{Method:}

The media used were Knight's semi-synthetic medium for Staphylococcus and synthetic medium for Shigella dysenteriae I.(12) 10cc of bacterial suspension of Staphylococcus grown in Knight's medium for 24 hours at $37^{\circ} \mathrm{C}$ was made, washed three times with saline, suspended in the original amount of saline and then diluted decimally two times with saline. 0.1cc of this final dilution was inoculated into each 5cc of the test medium. In the case of Shigella dysenteriae, a loopful of the broth culture grown for 24 hours at $37^{\circ} \mathrm{C}$ was transferred to the synthetic medium (without niacinamide), from which three successive subcultures were repeated in the same medium, each time one loopful of the preceding culture being used as inoculum. 0.1cc of the final subculture was inoculated into each 5cc of the test medium, or, in case neutral red was contained in the test medium, the final subculture was washed three times with saline and resuspended in one tenth of the original volume of saline, of which $0.2 \mathrm{cc}$ was inoculated into each 5cc of the test medium.

$D P N, P S A$ and niacinamide:

DPN was extracted from brewer's yeast by the method of Williamson and Green(23) and its purity was $19 \%$ as determined by Colowick and 
Kaplan's method(2) and also by estimating the amount of niacin (BrCNaniline method(4) ) therein. Molar concentration of DPN was calculated on the basis of this purity. PSA was synthesized from pyridine and fumic sulfuric acid(8) and used as sodium salt. Niacinamide was synthesized by our method(1).

Observation of growth:

Growth was observed by Colemann's Electrophotometer at the wave length of $500 \mathrm{~m} \mu$, or, in case of the media with neutral red, $650 \mathrm{~m} \mu$. The value of optical density is proportinal to bacterial number. Therefore, its logarithm was calculated and plotted in the figures.

\section{PSA in Staphylococcus}

It was shown that PSA can substitute niacin when used at the concentration higher than $10^{-4} \mathrm{M}$ and acts as a growth factor (Fig. 1). On the assumption that this is due to the inhibiting effects of PSA on the activity of DPN-nucleosidase, it was considered likely that the combined use of PSA and DPN might stimulate the growth and that, when given together with niacinamide, PSA might show no growth-stimulating effect, since niacinamide itself inhibits the action of DPN-nucleosidase of the brain(19). Any way, PSA may act with DPN in different way from that with niacinamide. Actually, stimulating effects were observed in the next experiment whereby both PSA and DPN were added, as shown in Fig. 2. PSA together with $10^{-6}$ to $10^{-8} \mathrm{M}$ of $\mathrm{DPN}$ remarkably accelerated the growth of Staphylococcus, whereas PSA together with $10^{-5} \mathrm{M}$ of DPN had no effect. $10^{-2} \mathrm{M}$ of PSA showed growth-stimulating effect in the later part of the growth period. PSA is not so much growth-inhibitory, so far as it is added at high concentrations as shown in Fig. 2.

Fig. 3 shows the growth observed in the medium containing PSA together with niacinamide. Growth-inhibitory effect of PSA could be observed after 24 hours, especially in case of the lower concentrations of niacinamide. It is interesting that, this time, contrary to the results of the preceding experiment with DPN, remarkable growth inhibitory, though not synergic, effects of the combination of PSA and niacinamide were observed.

\section{PSA in Shigella dysenteriae I}

So far, the investigation has been made on Staphylococcus which requires niacinamide as a growth factor. Then, what would be the effect 
Fig. 1. Effective type of PSA and neutral red.

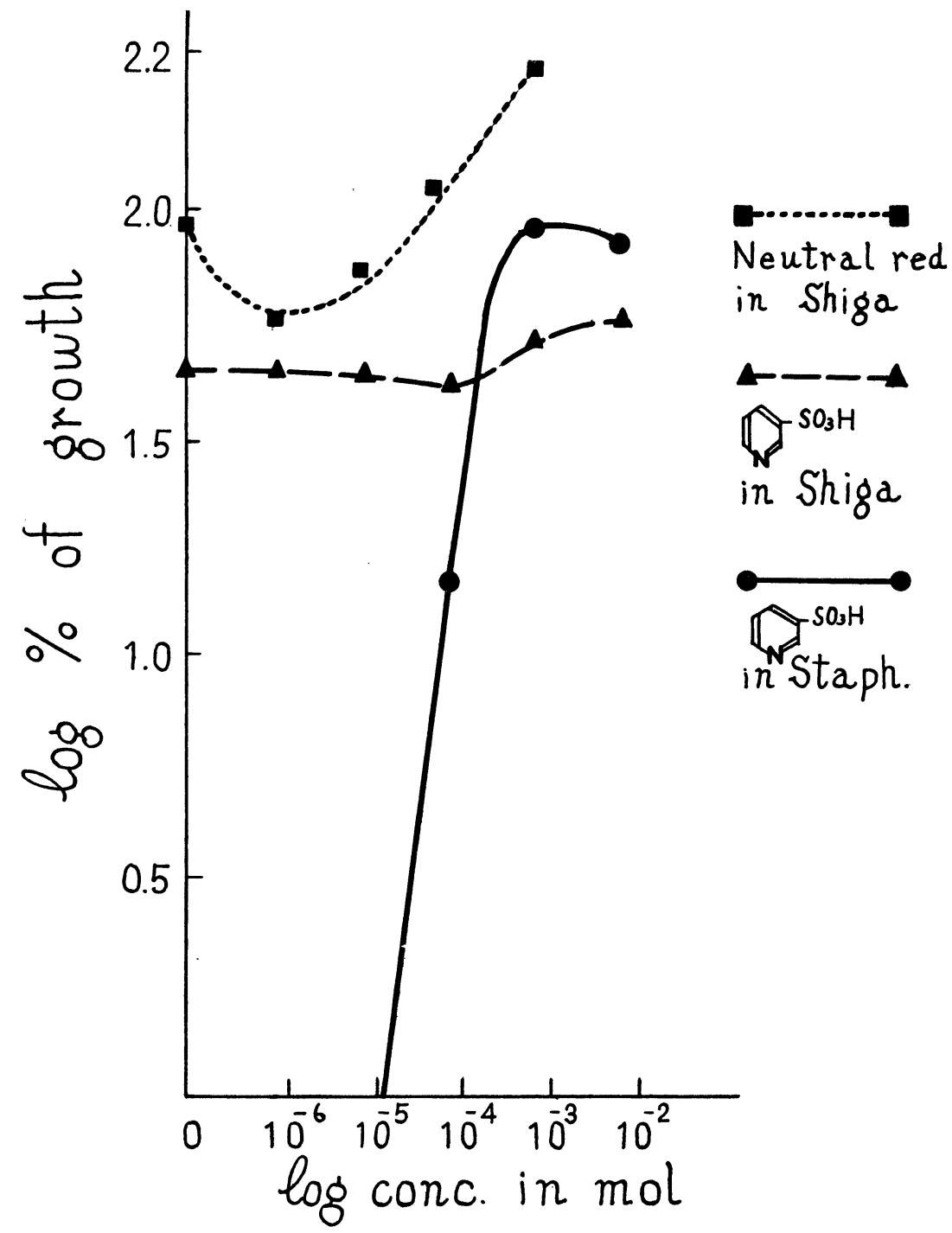

upon the growth of Shigella dysenteriae I which requires niacinamide as a growth-stimulating substance, being capable of synthesizing niacinamide to some extent but not sufficiently enough to support its own growth(11)? The results are shown in Fig. 4. After 36 hours' incubation, PSA added together with niacinamide was found to be growth-inhibitory and PSA together with DPN had no influence on the growth. 
Fig. 2. Relationship between DPN and PSA in Staphyiococcus aureus.
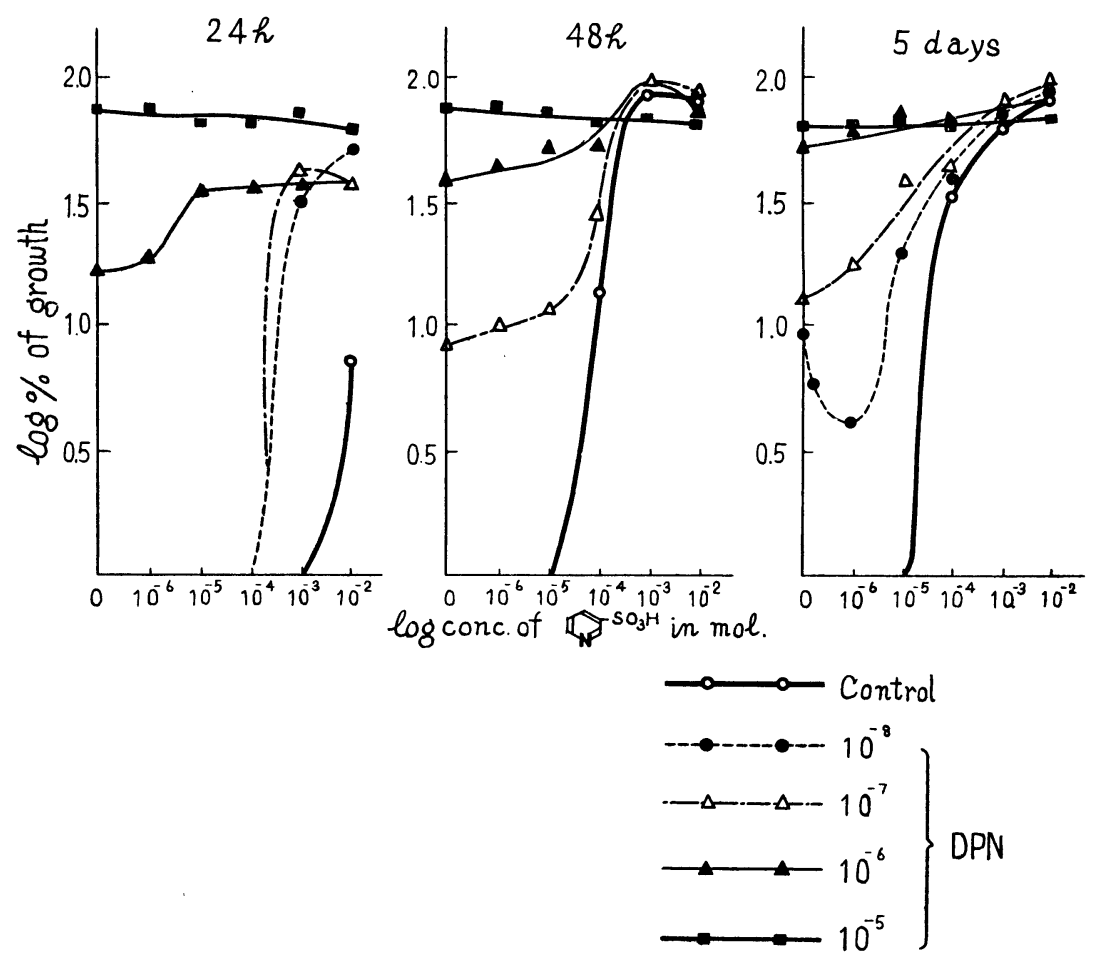

Fig. 3. Relationship between niacinamide and PSA in Staphylococcus aureus.
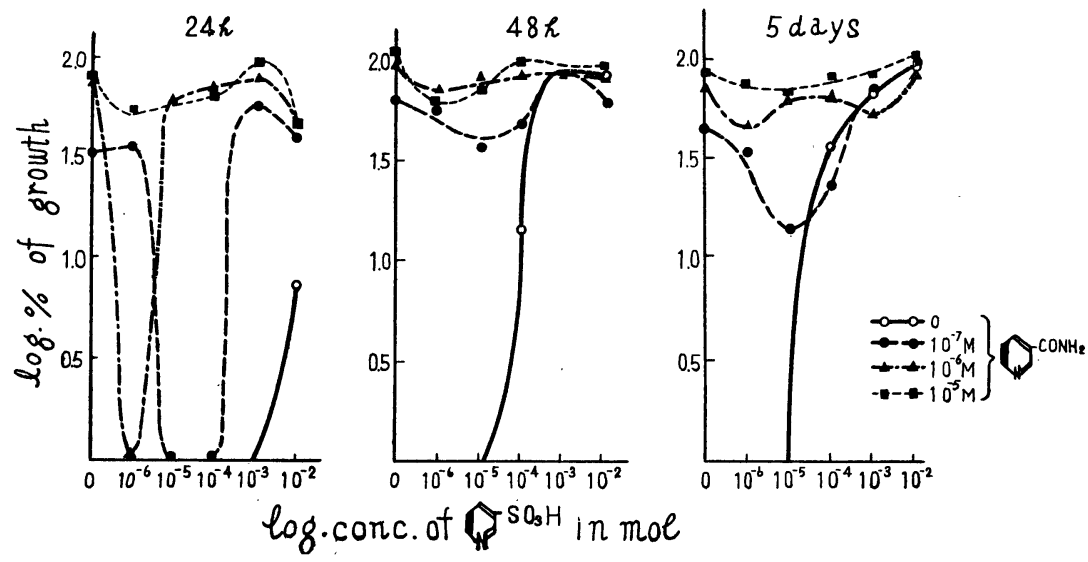
Fig. 4. Relationship between PSA and either DPN or niacinamide in Shigella dysenteriae.

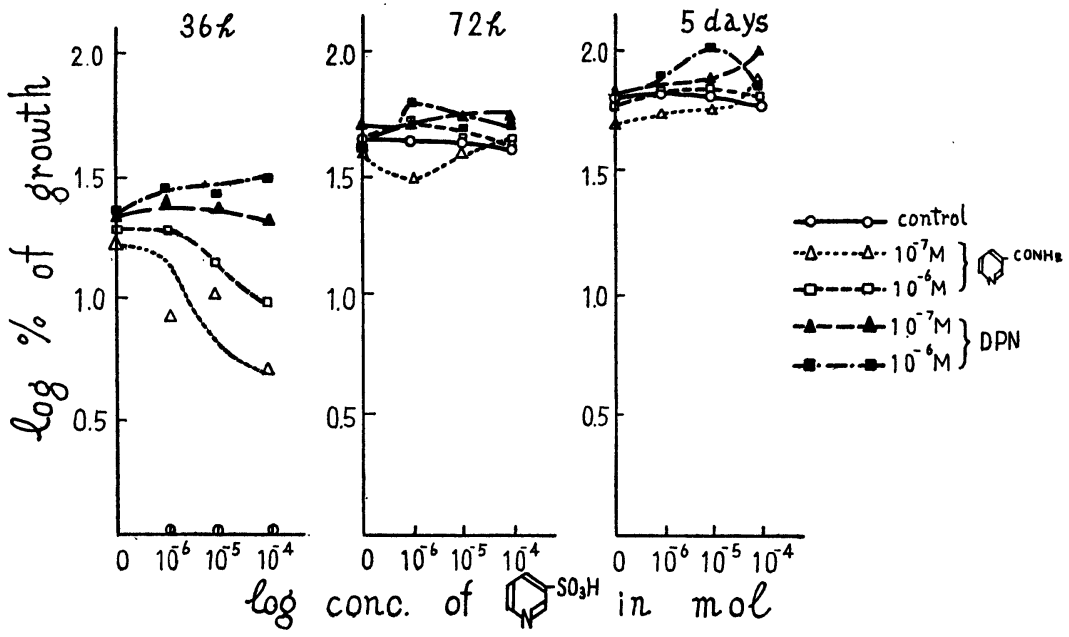

Fig. 5. Neutral red as a growth-accessory substance in Shigella dysenteriae

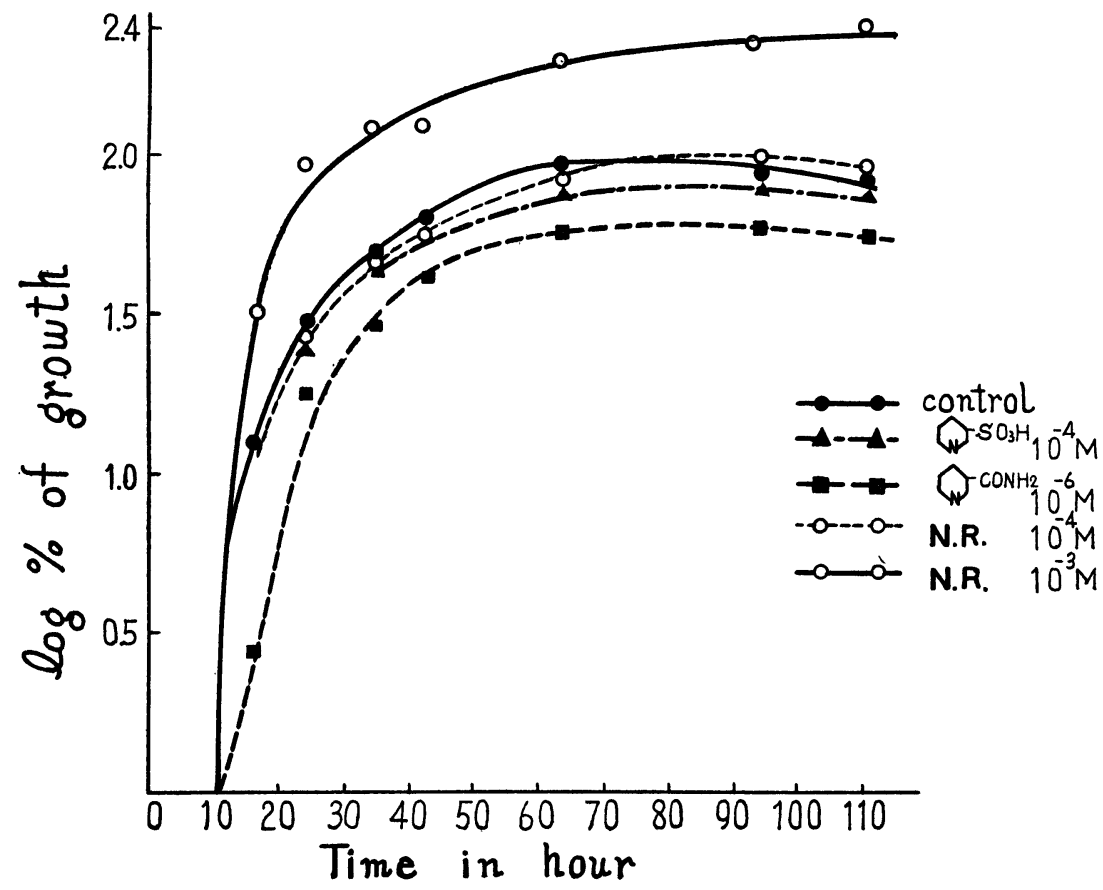




\section{Growth-stimulating effect of neutral red on Shigella dysenteriae I}

Neutral red is a typical inhibitor of DPN-nucleosidase in case it is an animal brain tissue preparation(19). It was thought that, if the activity of PSA as a growth factor is due to its inhibitory-effect against DPNnucleosidase, neutral red might also be a growth factor for Staphylococcus of a growth-stimulating substance for Shigella dysenteriae I. As shown in Fig. 5, the growth curve of Shigella dysenteriae I indicated that neutral red has remarkable growth-stimulating effect at the concentration of $10^{-3} \mathrm{M}$. Contrary to the case of PSA, neutral red at $10^{-2} \mathrm{M}$ completely inhibits the growth. Similar experiments on Staphylococcus failed to demonstrate the similar effect of neutral red, presumably due to strong growthinhibitory effect of neutral red on this bacteria, even in the presence of methyl-naphthoquinone ${ }^{(14)}$.

\section{Discussion}

According to the considerations made by Fildes' school(3), the growth factor can be considered as "essential metabolite" which can not be synthesized by bacteria. If the velocity of synthesis by bacteria of essential metabolite is negligibly slow, this essential metabolite works as a growth factor. If the velocity is limited (there might be varied steps) and slower than usual, this essential metabolite can become growth accessory substance. The quantitative order of growth factor during metabolism is usually within $\mathrm{m} \mu \mathrm{M} / \mathrm{mg} / \mathrm{hr}^{(15)}$.

The vitamin-activity of PSA appears to be slightly different from that of ordinary vitamins in the point that the quantitative order of PSA needed during growth period may probably be within $\mu \mathrm{M} / \mathrm{mg} / \mathrm{hr}$. It means that PSA is not a real growth factor, and that sulfonyl group of PSA can not be exchanged with carboxyl group during the growth period. The above findings show that PSA inhibits the activity of DPN-nucleosidase, thus exerting growth factor-like effects. Growth-inhibitory effects of PSA, when added together with niacinamide, may probably be due to the inhibition of the assimilation of niacinamide. It is comparable to the fact that pantoyltaurine can inhibit the assimilation as well as inactivation of pantothenic acid(15). In this meaning, the vitamin-activity of PSA can be understood to have the following mode. In the growth of bacteria which can synthesize DPN by themselves the DPN-synthesis is faster than its degradation, while in the growth of bacteria which are unable to synthesize 
DPN and require niacinamide as a growth factor the DPN synthesis is slower than its degradation. PSA is a substance which can control the balance between the synthesis and degradation of DPN. When it acts as an inhibitor of DPN-degradation (PSA with DPN), it apparently becomes a growth factor or a growth accessory substance, and when it acts as an inhibitor of niacinamide assimilation (PSA with niacinamide), it apparently becomes a growth-inhibitory substance instead. PSA, any may, can be a vitamin-like substance.

The findings described above should not be regarded as those restricted to the problem of DPN only. It can be suggested that other inhibitors of vitamin-destructive enzyme may act as vitamins in wider sense, since they protect the active form of vitamin against the vitamin-destructive enzyme; for example, pantoyltaurine against coenzyme-A destructive enzyme, sulfanilic acid against folic acid destructive enzyme and so on.

It has been known that DPN is less effective than niacinamide in term of their growth promoting effect at equimolecular concentration(22). For the interpretation of this phenomenon, there have been several considerations about factors accounting for it; for example, cell permeability(10), other substance than DPN and so on ${ }^{(20)}$. As confirmed in our experiments, DPN and niacinamide are equally effective at $10^{-5} \mathrm{M}$, whereby PSA has no effect. DPN is less effective than niacinamide at $10^{-6}, 10^{-7}$ and $10^{-8} \mathrm{M}$, whereby PSA remarkably promote the growth-stimulating effect of DPN. The bacterial growth in the presence of DPN at $10^{-6}$ to $10^{-8} \mathrm{M}$ together with PSA at $10^{-3} \mathrm{M}$ is equal to that of niacinamide alone at $10^{-6}$ to $10^{-8} \mathrm{M}$. Thus, the fact that DPN is less effective than niacinamide can be explained by the action of DPN-nucleosidase. As well known, Lactobacillus which has negligible DPN-nucleosidase can grow equally well in medium containing either DPN or niacinamide $(17,22)$.

\section{SUMMARY}

(1) PSA can substitute niacinamide at the concentrations of $10^{-4}$, $10^{-3}, 10^{-2} \mathrm{M}$ for the growth of Staphylococcus aureus Terashima.

(2) PSA is a growth accessory substance for Shigella dysenteriae I at the concentrations of $10^{-3}, 10^{-2} \mathrm{M}$.

(3) These two phenomena are thought to be due to the fact that PSA inhibits DPN-nucleosidase and hence acts as a vitamin. PSA added to the medium together with DPN accelerates to great extent the growth of 
Staphylococcus and Shigella dysenteriae I. PSA added to the medium together with niacinamide, on the contrary, inhibits the growth of both species of bacteria.

(4) Neutral red, an inhibitor of DPN-nucleosidase, can also become a growth-accessory substance for Shigella dysenteriae I.

(5) It is presumable from the data obtained above that inhibitor of vitamin-destructive enzymes may act as vitamins.

(6) Discussions were given on the problem that DPN is less effective than niacinamide even at equimolecular concentration.

\section{REFERENCES}

(1) Asano, M. and Mizuno, D.: Studies on the nutritional requirements of bacteria I. On the relationship between nutritional sources and growth factor for Proteus. Jap. Med. J., 1, 522-527 (1948).

(2) Colowick, S. P., Kaplan, N. P. and Ciotti, M. M.: The reaction of pyruvate nucleotide with cyanide and its analytical use. J. Biol. Ch. 191, 447-459 (1951).

(3) Fildes, P., Woods, D. D., McIlwain, H. Work, T. S., Rydon, H. N., Rose, F. L., Walker, J., Albert, A. and Stacey, M.: Antibiotic activity of growth-factor analogues. Nature, 162, 356 (1948).

(4) Kawashima, K.: Method of quantitative determination of nicotinic acid in animal and vegetable tissues. Kitasato Arch. exp. Med., 20, 109-112 (1948).

(5) Knight, B. C. J. G.: Vit. and Horm., 3, 105-228 (1945). Growth factors in microbiology.

(6) Kornberg, A. and Lindberg, O.: Diphosphopyridine nucleotide pyrophosphatase. J. Biol. Ch., 176, 665-677 (1948).

(7) Lwoff, A. and Querido, A.: La specificite de l'acide nicotinique, facteur de croissance pour B. Proteus. Compt. rend soc. biol., 130, 1569-1573 (1939).

(8) Machek, G.: Derivate der Pyridin-3-sulfonsäure. Mh. Chem., 72, 77-92 (1938).

(9) Mann, P. J. G. and Quastel, J. H.: Nicotinamide cozymase and tissue metabolism. Bioc. J., 35, 502-517 (1941).

(10) Matsunaga, J.: Influence of niacinamide on the respiration of Sonne type dysentery bacilli. Osaka Igakukaishi, 2, 1-4, (1950) (in Japanıse).

(11) Mizuno, D. and Kosaka, S.: Studies on the nutritional requirements of bacteria II. On the nutrition of Shigella dysenteriae. Jap. Med. J., 3, 99-105 (1950).

(12) Mizuno, D. and Irie, S.: Studies on nutritional requirements of bacteria IV Nitrogen requirement of wild type Shigella dysenteriae and the effect of niacin thereon. Jap. Med. J., 4, 279-282 (1951).

(13) McIlwain, H.: Pyridine-3-sulphonic acid and its amide as inhibitors of bacterial growth. Brit. J. exp. Path., 21, 136-147 (1940). 
(14) McIlwain, H.: The antistreptococcal action of iodinin, naphthoquinones and anthraquinones as its main natural antagonists. Bioc. J., 37, 265-271 (1943).

(15) Mcllwain, H. Interrelations in microorganisms between growth and the metabolism of vitamin-like substances. Adv. Enzym., 7, 409-460 (1947).

(16) McIlwain, H. and Hughes, D. E.: Decomposition and synthesis of cozymase by bacteria. Bioc. J., 43, 60-70 (1948).

(17) Mcllwain, H., Stanley, D. A., and Hughes, D. E.: The behaviour of Latobacillus arabinosus towards nicotinic acid and its derivatives. Bioc. J., 44, 153-158 (1949).

(18) McIlwain, H.: Breakdown of cozymase by a system from nervous tissue. Bioc. J., 44, 470-477 (1949).

(19) Mcllwain, H.: Properties of preparations from the control nervous system which degrade cozymase I and II; their connection with carbohydrate metabolism. Bioc. J., 46, 612-619 (1950).

(20) Saunders, F., Dorfman, A. and Koser, S. A.: The role of nicotinamide and related compounds in the metabolism of certain bacteria. J. Biol. Ch., 138, 69-82 (1941).

(21) Schlenk, F.: Nicotinamide Riboside. Arch. Bioch., 3, 93-103 (1943).

(22) Snell, E. E.: Bacterial nutrition-chemical factors, in Werkmann C. H. and Wilson, P. W. Bacterial physiology 214-255 (1951). Academic Press Inc. Publishers, New York.

(23) Williamson, S. and Green, D. E.: The preparation of coenzyme I from yeast. J. Biol. Ch., 135, 345-346 (1941).

(24) Woolley, D. W.: A study of antimetabolites. John Wiley \& Sons, Inc. New York, (1952). 